\title{
Awareness, Attitude and Expectations of Physiotherapy Students on Telerehabilitation
}

\author{
Mbada C.E ${ }^{1}$ - Baderinwa T.A. ${ }^{1} \cdot$ Sanuade C.T. ${ }^{1}$ Ademoyegun Adekola B. ${ }^{2} \cdot$ Clara Fatoye $^{3} \cdot$ Laminde Maikudi $^{1}$. \\ Francis Fatoye ${ }^{3}$
}

Accepted: 3 February 2021 / Published online: 18 February 2021

(c) International Association of Medical Science Educators 2021

\begin{abstract}
Background and Objective Explosion in information technology knowledge and utilization among young people, referred to as digital natives, seems less explored in the health sector and training. This study was aimed to assess awareness, attitude and expectations of physiotherapy students on telerehabilitation.

Methods This cross-sectional survey employed systematic probability sampling technique to recruit 200 physiotherapy students. A self-developed questionnaire which was tested for its face and content validity was used to obtain data. Data was analysed using descriptive and inferential statistics. Alpha level was set at $p<0.05$.

Results The mean age of the respondents was $21.2 \pm 2.04$ years. There was higher prevalence of moderate awareness $(43 \%)$ and positive attitude towards telerehabilitation (39\%). Majority of the respondents (62\%) had high expectation towards future telerehabilitation products and services. There was significant association between level of awareness of telerehabilitation and age $\left(X^{2}=7.119 ; p=0.001\right)$.

Discussion The responding students in this study are by age in the class of digital natives, who should be conversant with technology. This could account for the higher moderate level of awareness of telerehabilitation. However, the higher rates of negative attitude towards telerehabilitation could be attributed to prevailing barriers to its utilization in Nigeria. Nonetheless, a large percentage of the students had high expectations for the future of telerehabilitation.

Conclusion Nigerian physiotherapy students have moderate awareness and high expectation for future telerehabilitation applications. However, a larger number of them hold negative attitude towards it use.
\end{abstract}

Keywords Physiotherapy · Students · Telerehabilitation · Information communication technology $\cdot$ Digital natives ·

Healthcare

\section{Introduction}

In recent years, technology has revolutionized all aspects of medical rehabilitation, from provision of cutting-edge assessment to the actual delivery of specific interventions [1]. Telerehabilitation which is described by the American

Ademoyegun Adekola B.

aademoyegun@gmail.com

1 Department of Medical Rehabilitation, College of Health Sciences, Obafemi Awolowo University, Ile-Ife, Nigeria

2 Department of Physiotherapy, Ladoke Akintola University of Technology Teaching Hospital, Osogbo, Nigeria

3 Department of Health Professions, Faculty of Health, Psychology and Social Care, Manchester Metropolitan University, Manchester, UK
Telemedicine Association as the delivery of rehabilitation services via information and communication technologies to adults and children by a broad range of professionals is redefining the rehabilitation landscape and services [2]. Some of these services include therapeutic interventions, remote monitoring of progress, education, consultation, training and a means of networking for people with disabilities [3]. The impact of telerehabilitation ranges from patients' easy access to a specialist, facilitation of continuity of care and low cost to clinician-centered benefits [4-6].

Available systematic reviews have explored impacts and acceptability of telerehabilitation from the patients' perspective [7-11]. However, the hope for the future is to continue to develop and use new, innovative technologies that will transform current practice and make telerehabilitation an integral part of healthcare [3]. 
Perpetuating any professional culture or practice lies with the paradigm of the students. Students represent the next generation of any profession or discipline and uptake of telerehabilitation can be enhanced when potential graduate physiotherapists are knowledgeable and have positive attitudes towards its utilization. Therefore, there is a need to evaluate students' awareness, attitudes and expectations in empirical perspective.

Current and future utilization of telerehabilitation is rapidly expanding. This relatively new discipline requires to be accepted by both consumers and providers. To date, less attention has been paid to evaluating awareness about telerehabilitation and anticipations towards its future utilization. Therefore, this study was aimed to assess the awareness, attitude and expectations for telerehabilitation among physiotherapy students.

\section{Materials and Methods}

Ethical approval for this study was obtained from the Health Research and Ethics Committee of the Institute of Public Health (IPHOAU/12/1449), Obafemi Awolowo University, Nigeria. Informed consent was sought and obtained from all the respondents.

A cross-sectional study survey was utilized in this study and a probability sampling technique using a systematic approach was used to recruit respondents from undergraduate students studying physiotherapy in the Department of Medical Rehabilitation, Obafemi Awolowo University, Nigeria. Students who were at least in 200 levels were recruited. The participants were equally distributed across class (25\% per class) and gender (50\% per gender). The list of all students in the Department was obtained and was stratified by class and gender. In order to achieve proportionate samples, starting from the first candidate on the list, arranged according to their matriculation number, every other candidate was invited into the study until the maximum expected number per quota was reached. The sample size for this survey was determined using Yamane formula: $n=N /\left[1+N(e)^{2}\right]$ [12], where $n$ is the sample size, $N$ the population size (400) and $e$ is the level of precision (0.05). Therefore, 200 respondents were recruited for this study.

A self-developed, self-administered questionnaire, which had its face and content validity tested, was used to assess awareness, attitude and expectation about telerehabilitation. The questionnaire had three sections, each containing questions on each of the concepts/ parameters assessed on this study. Some of the items on the tool were scored using a 5-point Likert scale: disagree (SD), strongly disagree (SD), I do not know (IDK), agree (A) and strongly agree (SA).

\section{Data Analysis}

Descriptive statistics of frequency, percentage, mean and standard deviation were used to summarize the data. Chi-square test was used to assess the association between attitudes, awareness and expectations with the socio-demographic characteristics (age, sex, level of study) of the students. This statistical analysis was performed using IBM SPSS (Ver. 21). Alpha level was set at $p<0.05$.

\section{Results}

\section{Socio-demographic Characteristics}

Table 1 shows the socio-demographic characteristics of respondents. The mean age of the participants was $21.2 \pm 2.04$ years. However, $150(75 \%)$ respondents were in $20-25$ age range. The graphic representation of their socio-demographics is shown in Fig. 1.

\section{Awareness About Telerehabilitation}

Most of the respondents were aware of telerehabilitation platforms (76.5\%) while the main source of awareness of respondents about telerehabilitation platforms was school (61.4\%) followed by lecture, workshop and seminar $(26.1 \%)$ (Table 2). More than $70 \%$ of the respondents which claimed that they were not aware of telerehabilitation put lack of information or lack of inclusion of telerehabilitation in school curriculum as the reason, and $14.9 \%$ respondents claimed they have not seen telerehabilitation in practice as the reason.

Table 1 Socio-demographic data of respondents $(N=200)$

\begin{tabular}{llll}
\hline Variable & Frequency $(n)$ & Percentage $(\%)$ & Mean \pm SD \\
\hline Age (years) & & & \\
$<20$ & 43 & 21.5 & $21.2 \pm 2.04$ \\
$20-25$ & 150 & 75 & \\
$>25$ & 7 & 3.5 & \\
Sex & & 50 & \\
Male & 100 & 50 & \\
Female & 100 & & \\
Level of study & & 25 \\
200 level & 50 & 25 \\
300 level & 50 & 25 \\
400 level & 50 & 25 \\
500 level & 50 &
\end{tabular}


Fig. 1 Bar graph showing socio-demographic characteristics of respondents $(N=200)$

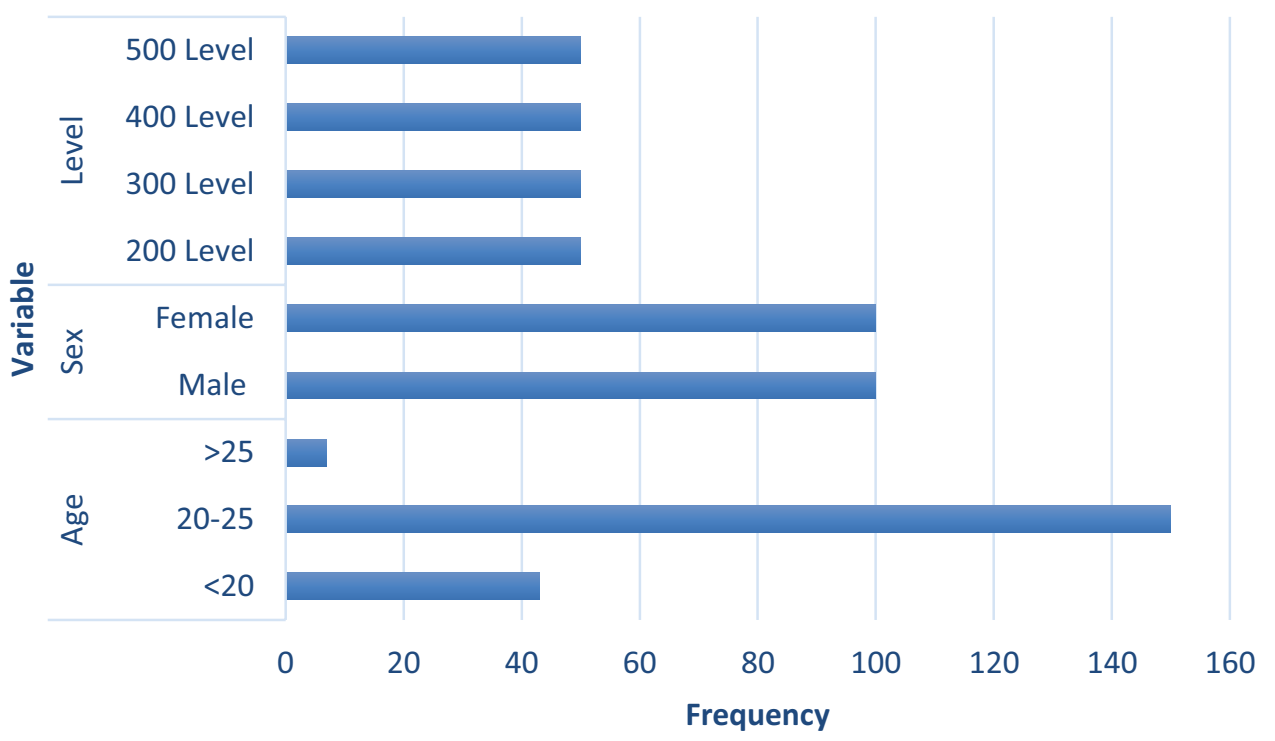

One hundred and sixty-one (80.5\%) of the respondents asserted that telerehabilitation is an information and communication technology platform used to provide rehabilitation services to remote places while $72 \%$ of the respondents claimed telerehabilitation is the same as telemedicine. More than half of the respondents (61.5\%) agreed that telerehabilitation will save travelling time and money for obtaining an expert opinion (Table 3). The respondents who correctly answered questions on awareness about telerehabilitation were categorized into quartiles. The maximum score on awareness score is 10 (10 items). The quartiles used in this study include quartile $1(0-50 \%)$, correct score of 1-5 categorized as low awareness; quartile $2(50-75 \%)$, correct score of

Table 2 Physiotherapy students' awareness about telerehabilitation platforms $(N=200)$

\begin{tabular}{lll}
\hline Item & $n$ & $\%$ \\
\hline
\end{tabular}

Are you aware about telerehabilitation platforms such as skype, facetimes, etc.

$\begin{array}{lll}\text { Yes } & 153 & 76.5 \\ \text { No } & 47 & 23.5\end{array}$

If no, why do you think you were not aware of these telerehabilitation platforms?

$\begin{array}{llr}\text { No information/curriculum } & 33 & 70.2 \\ \text { Not seen in practice } & 7 & 14.9 \\ \text { Technical problem reasons } & 4 & 8.5 \\ \text { No response } & 3 & 6.4\end{array}$

How did you get to know about telerehabilitation?

$\begin{array}{llr}\text { Lecture/workshop/seminar } & 40 & 26.1 \\ \text { School } & 94 & 61.4 \\ \text { ternet } & 11 & 7.2 \\ \text { Hospital/practice } & 5 & 3.3 \\ \text { Others } & 5 & 3.3\end{array}$

6-7 categorized as average awareness; and quartile 3 (75-100\%), correct score of 8-10 categorized as high awareness. The multidimensional level of respondents' awareness of COVID-19 is shown in Fig. 2.

As shown in Table 6, most respondents (43\%) have average awareness level of telerehabilitation while eighty-two $(41 \%)$ respondents have high awareness level. There was significant association between the level of awareness of telerehabilitation and age $\left(X^{2}=22.312\right.$; $p=0.001$ ), but not with gender and class level (Table 7).

\section{Attitude Toward Telerehabilitation}

One hundred and forty-three (71.5\%) respondents reported their comfortability with telerehabilitation applications as shown in Table 4. One hundred and forty-three (71.5\%) of the respondents believed that telerehabilitation should be implemented in all hospitals, while $79 \%$ respondents believed that they could be more productive quickly using telerehabilitation. However, many respondents $(60.5 \%)$ reported that they will accept telerehabilitation only after seeing reports of patients being treated by it, and one hundred and thirty-three respondents $(66.5 \%)$ believed telerehabilitation can never replace face-to-face consultation. Also, attitude was grouped into positive and negative towards telerehabilitation. Attitude was considered positive if the respondents affirmed or decline to a positively or negatively constructed question, respectively, and vice versa for negative attitude. Majority of respondents reported negative attitudes to telerehabilitation when compared with other modalities of treatment (61\%) as shown in Table 6. Showing with a bar graph in Fig. 3 are the respondents' characteristics and their attitudinal type. There was no significant association 
Table 3 Awareness of components of telerehabilitation $(N=200)$

Item Disagree $n(\%)$ Agree $n(\%)$

Telerehabilitation refers to the use of information and communication technologies (ICT) to provide rehabilitation

$39(19.5)$

$161(80.5)$ services to people remotely in their home or other environments

Telerehabilitation services include therapeutic interventions, remote monitoring of progress, education, consulta- 44 (22) tion, training and a means of networking for people with disabilities

Telerehabilitation is the same as telemedicine

Telerehabilitation involves only physiotherapy and occupational therapy

Telerehabilitation enables patients to take control of their management unlike

the face to face clinic approach

Telerehabilitation cuts down the associated travel costs and time spent travelling for both the healthcare provider and patient

Telerehabilitation enables clinicians to remotely engage and deliver patient care outside of the medical setting, thus eliminating the issue of distance between clinician and patient

I think the visits provided over the telerehabilitation systems are as the same as in-person visits

between the attitude towards use of telerehabilitation and age $\left(X^{2}=4.146 ; p=0.126\right)$ and $\operatorname{sex}\left(X^{2}=3.026 ; p=0.082\right)$. However, there was significant association between attitude to use of telerehabilitation and level of study of respondents $\left(X^{2}=4.119 ; p=0.042\right)$ (Table 8).

\section{Expectation Toward Telerehabilitation}

Table 5 shows the expectation characteristics of the respondents toward telerehabilitation. One hundred and forty-three $(71.5 \%)$ respondents expect telerehabilitation

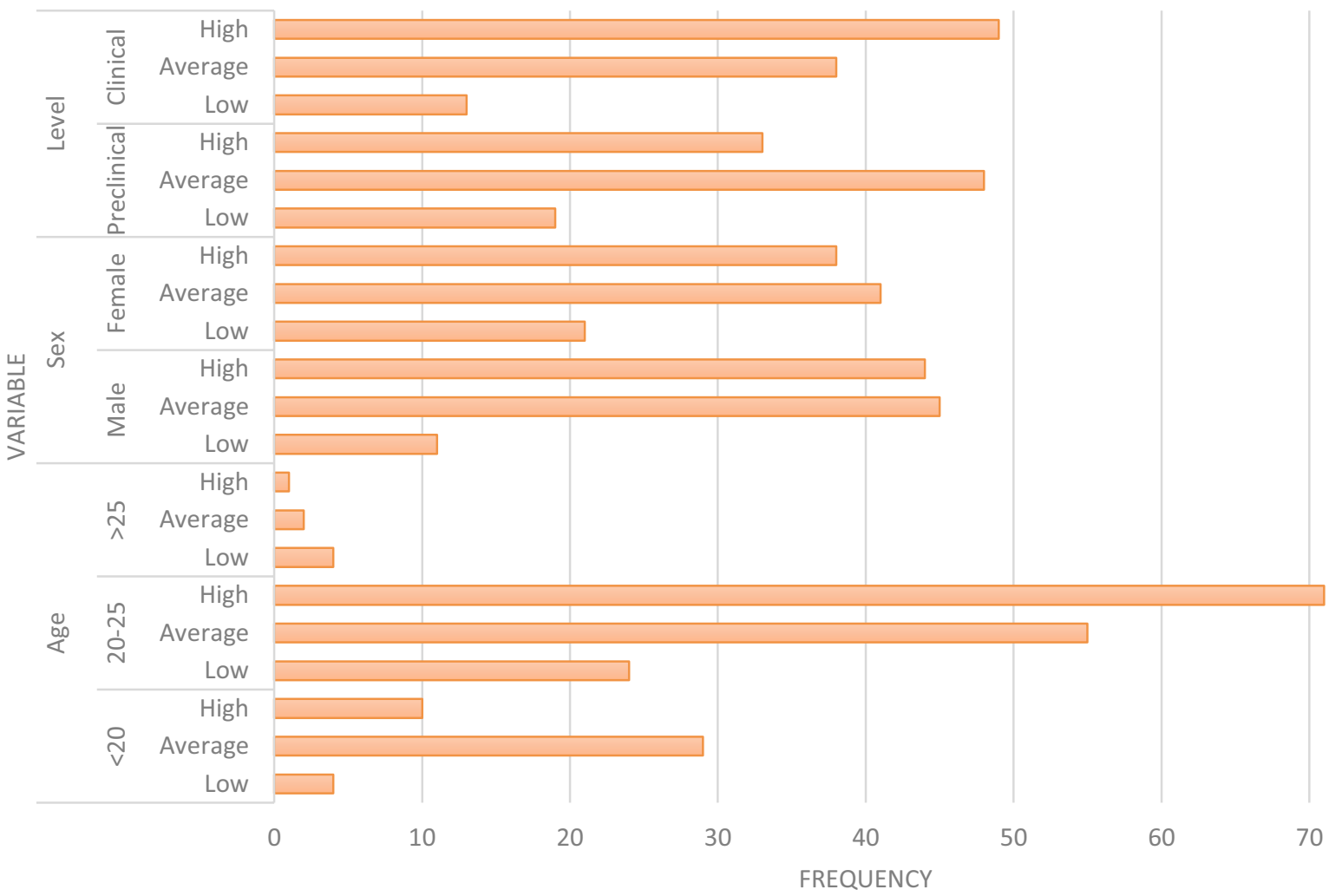

Fig. 2 Bar graph showing multidimensional level of respondents' awareness of telerehabilitation $(N=200)$ 
Table 4 Attitude characteristics of the respondents $(N=200)$

\begin{tabular}{|c|c|c|}
\hline Item & Disagree $n(\%)$ & Agree $n(\%)$ \\
\hline Am comfortable with telerehabilitation applications & $57(28.5)$ & $143(71.5)$ \\
\hline $\begin{array}{l}\text { I have issues with number of capable internet devices like smartphone, tablets, and computer as am not use to } \\
\text { them }\end{array}$ & $48(24)$ & $152(76)$ \\
\hline Telerehabilitation is convenient as I may not have to leave my environment & $52(27.5)$ & $148(72.5)$ \\
\hline I find it easy to learn and use telerehabilitation system & $45(22.5)$ & $155(77.5)$ \\
\hline I believe I could be more productive quickly using Telerehabilitation & $42(21)$ & $158(79)$ \\
\hline The way I interact with telerehabilitation system is satisfactory & $34(13)$ & $166(83)$ \\
\hline I like using telerehabilitation systems & $29(14.5)$ & $171(85.5)$ \\
\hline Telerehabilitation systems are simple and easy to understand & $107(53.5)$ & $91(46.5)$ \\
\hline Telerehabilitation system is able to do everything I would want it to be able to do & $104(52)$ & $96(48)$ \\
\hline Telerehabilitation will help in easy access to health for rural patients & $84(42)$ & $116(58)$ \\
\hline I presume patients would feel comfortable in being treated by Telerehabilitation & $102(51)$ & $97(48.5)$ \\
\hline Telerehabilitation can never replace face-to-face consultation & $66(30)$ & $133(66.5)$ \\
\hline I could not rely on a consultation via telerehabilitation & $99(49.5)$ & $98(49)$ \\
\hline I will accept telerehabilitation only after seeing reports of patients being treated by it & $79(39.5)$ & $121(60.5)$ \\
\hline Due to lack of sufficient knowledge of telerehabilitation technology and application I am unable to practice it & $105(52.5)$ & $95(47.5)$ \\
\hline Due to the large number of patients in my practice, I am not interested in Telerehabilitation & $153(76.5)$ & $47(23.5)$ \\
\hline Telerehabilitation is a waste of my valuable time & $169(84.5)$ & $31(15.5)$ \\
\hline If a charge is made for telerehabilitation then I will use it & $107(53.5)$ & $92(46)$ \\
\hline I felt I was able to express myself effectively using telerehabilitation system & $122(61)$ & $78(39)$ \\
\hline
\end{tabular}

to be implemented in all hospitals while $76 \%$ reported that updates of each session should be sent to patients/clinician to aid use of telerehabilitation. One hundred and sixty-six (83\%) respondents reported that telerehabilitation should be included in university curriculum and various academic platforms such as workshops, seminars etc (Tables 6, 7 and 8). Questions on expectation of respondents on telerehabilitation were constructed positively, and positive response was categorized into low expectation (1-2 score), average expectation (3-4 score) and high expectation (5-7 score). The maximum score for expectation is 7 (7 items). Table 9 and Fig. 4 show the association between the participants' level of expectation for telerehabilitation and their socio-demographic characteristics. There was significant association between the level of expectation for telerehabilitation and each of age $\left(X^{2}=38.444\right.$; $p=0.001)$ and level of study $\left(X^{2}=19.165 ; p=0.001\right)$ of the respondents.

\section{Discussion}

This study was aimed to assess the awareness, attitude and expectations for telerehabilitation among physiotherapy students. The mean age of the participants in this study showed that they were young adults with age range showing that they were all close in age to one another. Thus, it can be inferred that these respondents should be aware and informed about the use of information, communication and technology either through mobile apps, computer system or an electronic gadget. Young people, especially the millennial, are born in a digital world and are reported to be good at using technology because they are digital natives [13]. Current students are among the first generation of "digital natives" who are well versed in the incorporation of technology into social interaction and are well positioned to apply advances in communications to patient management [14]. Expectedly, there was significant association between the level of awareness of telerehabilitation and age of the respondents confirming that they are really generation of digital natives. A survey by Aminu et al. stated that smartphone adoption is on the upswing in Nigeria, as well as the number of Nigeria's mobile subscribers, and the number of its Internet users [15]. There are studies indicating high usage of information technology and information systems among Nigerian students [16, 17]. However, there is a dearth of studies on the awareness and use of information technology and systems for health purpose among Nigerian students [18-20]. Therefore, this study is novel in confirming this awareness in Nigeria.

Skype, facetimes and video-conferencing constitute the most common source of awareness for telerehabilitation for physiotherapy students than from the classroom. These digital platforms are receiving increasing exploration especially from youth in developing countries who desire to be in tandem with information technology strides 


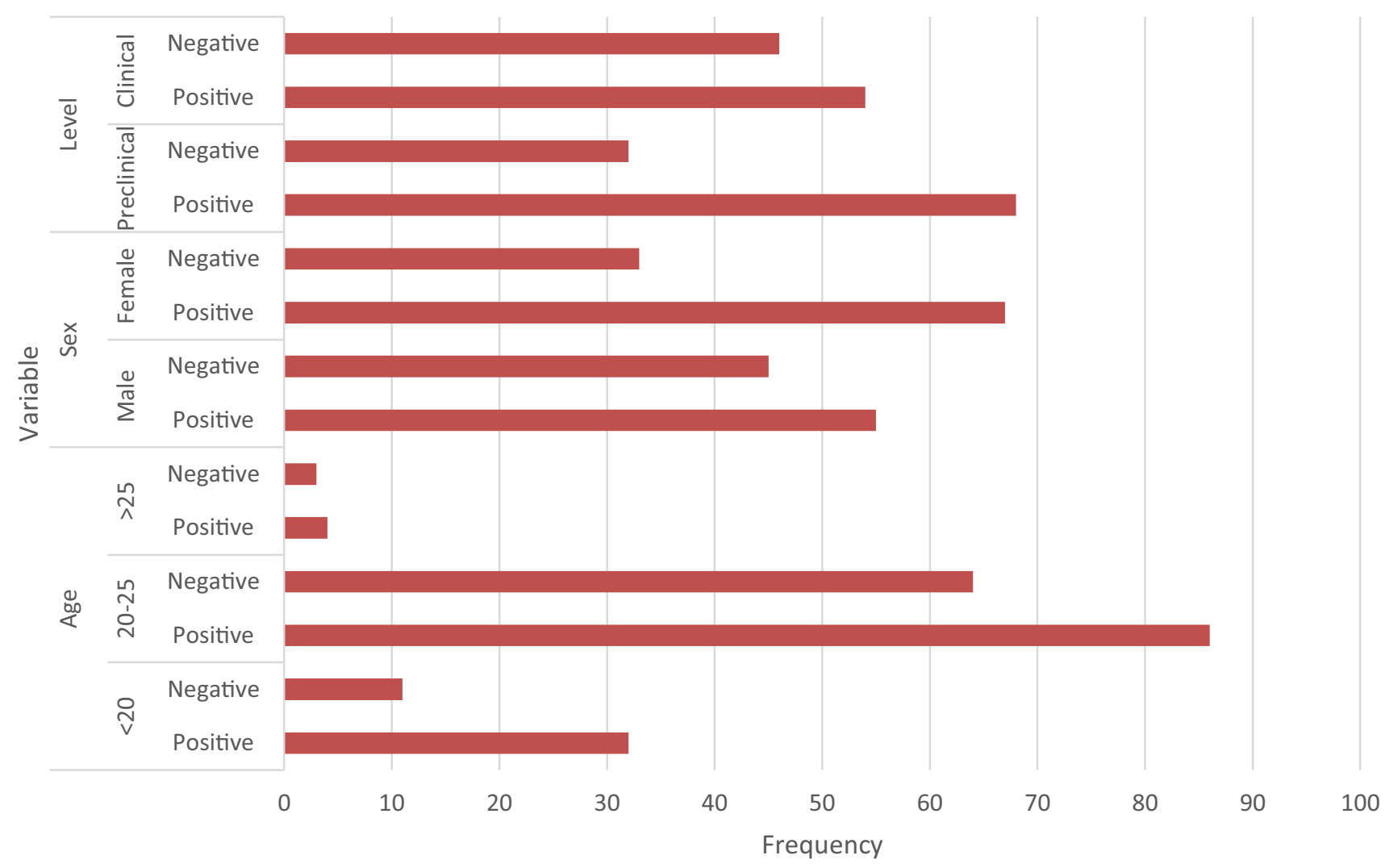

Fig. 3 Bar graph showing respondents' characteristics and attitudinal type to telerehabilitation $(N=200)$

in the developed contexts [21]. Thus, awareness of telerehabilitation for physiotherapy students in this study came from social media and online education platform rather than classroom. Some of the participants also reported they have not seen telerehabilitation being used in clinical practice, as they were only conversant with conventional rehabilitation. This submission is suggestive that clinicians are yet to adopt telerehabilitation, and this is in line with a previous report which stated that professional portability and training are generic barriers to tele-health [3]. Moreover, it may further limit the use or uptake of telerehabilitation in the clinical settings because a report from Australian Physiotherapy Association [22] has postulated that the future of telerehabilitation will depend on training of physiotherapists at the undergraduate and postgraduate level in the appropriate use of technologies for telerehabilitation practice. Therefore, in line with the views of the participants in this study, educating Nigerian physiotherapy students in the field of telerehabilitation by inclusion of telerehabilitation-related courses in university curriculum and training at various platforms such as workshops and seminars may bring development to the field of telerehabilitation in Nigeria. The finding of this study affirms earlier submission of lack of widespread use of mobile phones as a result of affordability [23] and it is quite discouraging that mobile phones, which is one of

Table 5 Expectation characteristics of the respondents $(N=200)$

\begin{tabular}{|c|c|c|}
\hline Item & Disagree $n(\%)$ & Agree $n(\%)$ \\
\hline Telerehabilitation should be implemented in all hospitals & $57(28.5)$ & $143(71.5)$ \\
\hline Feedback should be sent after each session to aid my use of Telerehabilitation & $48(24)$ & $152(76)$ \\
\hline Network availability in remote areas should be enhanced for Telerehabilitation to be functional & $55(27.5)$ & $152(72.5)$ \\
\hline Patient-clinician acceptability of telerehabilitation is needed or should be improved & $45(22.5)$ & $155(77.5)$ \\
\hline Confidentiality, patient privacy, abuse of use by patients, internet fraud and quackery should be minimized to zero & $42(21)$ & $158(79)$ \\
\hline $\begin{array}{l}\text { Telerehabilitation should be included in university curriculum and various platforms such as workshops, seminars } \\
\text { etc }\end{array}$ & $34(17)$ & $166(83)$ \\
\hline Adequate funding and policy for telerehabilitation system in Nigeria is needed & $29(14.5)$ & $171(85.5)$ \\
\hline
\end{tabular}


Table 6 Level of awareness, attitude and expectations for telerehabilitation $(N=200)$

\begin{tabular}{lll}
\hline Variable & Frequency & Percentage \\
\hline Awareness & 32 & 16 \\
Low & 86 & 43 \\
Average & 82 & 41 \\
High & & \\
Attitude & 122 & 61 \\
Negative & 78 & 39 \\
Positive & & \\
Expectation & 19 & 9.5 \\
Low & 57 & 28.5 \\
Average & 124 & 62 \\
High & & \\
\hline
\end{tabular}

the simplest medium through which telerehabilitation can be carried out, is not widely available to students, not to mention sophisticated technologies such as image-based technologies, sensor-based technologies and virtual realitybased telerehabilitation systems which have been in use for years in developed countries in various diseases amenable to physiotherapy [8-11]. Therefore, majority of the participants got their knowledge about telerehabilitation through school followed by lectures, workshop and seminars. Only few of the students got the knowledge of telerehabilitation through social media platforms while some of them got the knowledge from clinical practice.

Furthermore, the findings of this study revealed that respondents have a positive attitude towards telerehabilitation as it was comfortable, convenient, easy to use as well as productive and this can be affirmed through a number of factors presented as advantages of telerehabilitation services. These include continuity of patient care through the remote provision of services,

Table 7 Association between levels of awareness of telerehabilitation and socio-demographic characteristics $(N=200)$

\begin{tabular}{llllll}
\hline Variable & \multicolumn{2}{l}{ Level of awareness } & \multirow{2}{*}{$X^{2}$} & $p$ value \\
\cline { 2 - 4 } & Low & Moderate & High & & \\
& $n(\%)$ & $n(\%)$ & $n(\%)$ & & \\
\hline Age & & & & & \\
$\quad<20$ & $4(9.3)$ & $29(67.4)$ & $10(23.3)$ & 23.312 & 0.001 \\
$20-25$ & $24(16)$ & $55(36.7)$ & $71(47.3)$ & & \\
$>25$ & $4(57.1)$ & $2(28.6)$ & $1(14.3)$ & & \\
Sex & & & & & \\
$\quad \begin{array}{l}\text { Male } \\
\text { Female }\end{array}$ & $11(11)$ & $45(45)$ & $44(44)$ & 3.750 & 0.153 \\
Level & $21(21)$ & $41(41)$ & $38(38)$ & & \\
$\quad \begin{array}{l}\text { Preclinical } \\
\text { Clinical }\end{array}$ & $19(19)$ & $48(48)$ & $33(33)$ & 5.410 & 0.67 \\
\hline
\end{tabular}

Table 8 Association between levels of attitude towards telerehabilitation and socio-demographic characteristics $(N=200)$

\begin{tabular}{lllll}
\hline Variable & Attitude & & $X^{2}$ & $p$ value \\
\cline { 2 - 3 } & $\begin{array}{l}\text { Negative } \\
n(\%)\end{array}$ & $\begin{array}{l}\text { Positive } \\
n(\%)\end{array}$ & & \\
\hline Age & & & & \\
$\quad<20$ & $32(74.4)$ & $11(25.6)$ & 4.146 & 0.126 \\
$20-25$ & $86(57.3)$ & $64(42.7)$ & & \\
$>25$ & $4(57.1)$ & $3(42.9)$ & & \\
Sex & & & & \\
$\quad$ Male & $55(55)$ & $45(45)$ & 3.026 & 0.082 \\
$\quad$ Female & $67(67)$ & $33(33)$ & & \\
Level & & & & \\
$\quad \begin{array}{l}\text { Preclinical } \\
\text { Clinical }\end{array}$ & $68(68)$ & $32(32)$ & 4.119 & 0.042 \\
\hline
\end{tabular}

reduced transportation cost and time savings on both the healthcare system and the patient, heightened ability to control the timing, intensity and sequencing of the intervention, positive effects of rehabilitating a patient in their own social and vocational environment and the potential environmental impacts of reducing travel [24]. The participants in this study also affirm that telerehabilitation does not only help in easy access to health services but also prevents worsening or deterioration of health status as a result of strenuous travelling.

The respondents reported that telerehabilitation may not be able to do everything, and therefore doubted its effectiveness. A study by Rosen [25] concluded that technical savviness, hearing and visual problems of elderly patients may have affected the effectiveness of telerehabilitation used to monitor elderly patients with

Table 9 Association between levels of expectation for telerehabilitation and socio-demographic characteristics $(N=200)$

\begin{tabular}{llllll}
\hline Variable & \multicolumn{2}{l}{ Level of awareness } & $X^{2}$ & $p$ value \\
\cline { 2 - 4 } & Low & Moderate & High & & \\
& $n(\%)$ & $n(\%)$ & $n(\%)$ & & \\
\hline Age & & & & & \\
$\quad<20$ & $9(20.9)$ & $22(51.2)$ & $12(27.9)$ & 38.44 & 0.001 \\
$20-25$ & $8(5.3)$ & $31 .(20.7)$ & $111(74)$ & & \\
$>25$ & $2(28.6)$ & $4(57.1)$ & $1(14.3)$ & & \\
Sex & & & & & \\
$\quad \begin{array}{lllll}\text { Male } \\
\text { Female }\end{array}$ & $9(9)$ & $34(34)$ & $57(57)$ & & \\
Level & & & & & \\
$\quad \begin{array}{l}\text { Preclinical } \\
\quad 10(10)\end{array}$ & $42(42)$ & $48(48)$ & 19.165 & 0.001 \\
$\quad$ Clinical & $9(9)$ & $15(15)$ & $76(76)$ & & \\
\hline
\end{tabular}




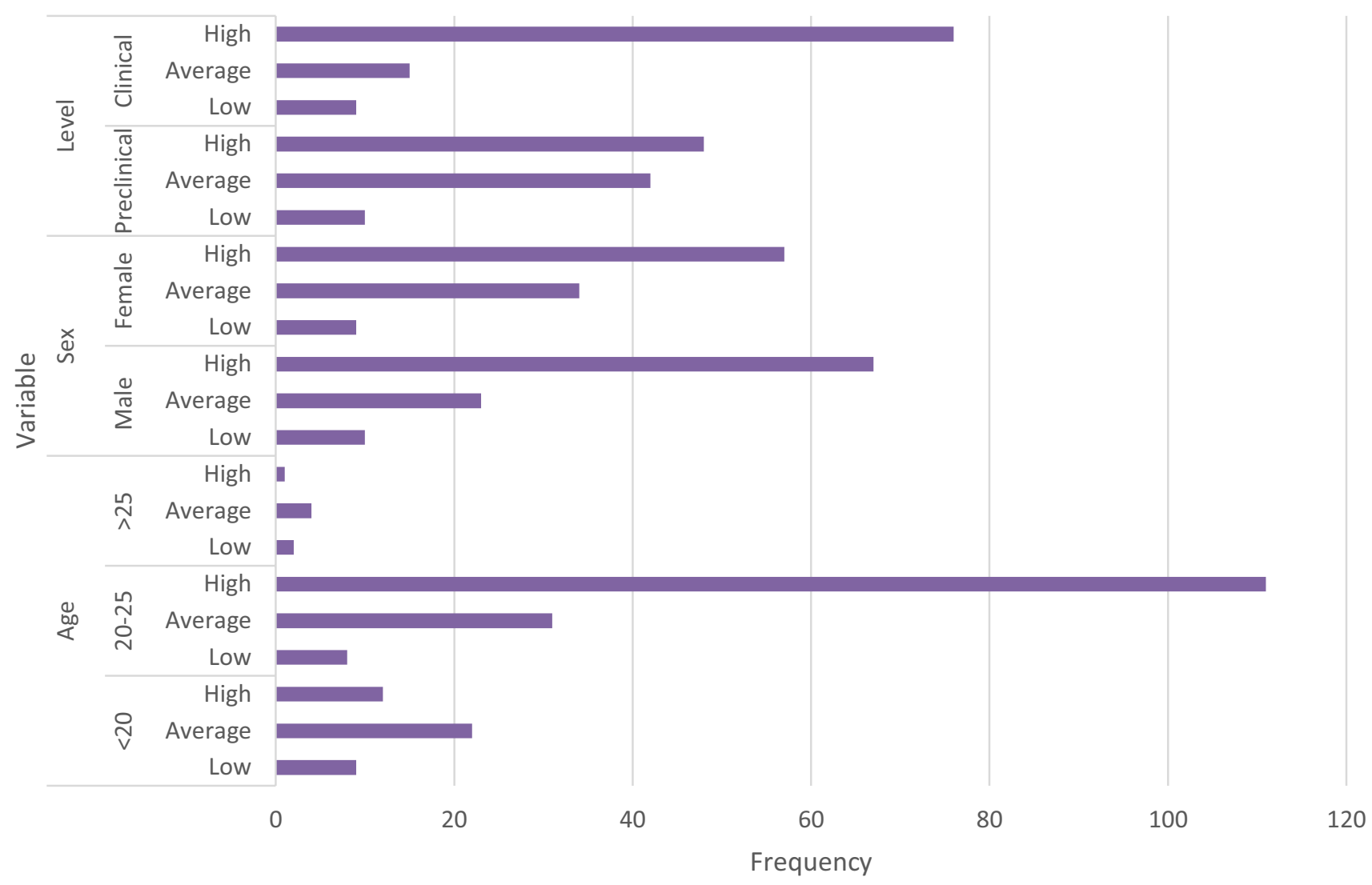

Fig. 4 Respondents' characteristics and their level of expectation toward telerehabilitation $(N=200)$

chronic lung disease living in rural areas. In addition, some of the respondents opined that difficulty in learning to use technology may have an impact on how and if a telerehabilitation will replace current clinical practice. This can be affirmed by the finding in the study by Brennan and Barker [26] which showed that the barrier to technology adoption reveals the learning curve for users on both the clinical and remote sides. Users must understand a technology or software and be able to independently adjust settings and maintain the technology. Therefore, technology abandonment may occur (even in the face of unmet clinical needs), when users decide that a telerehabilitation technology is too difficult to learn or requires high levels of maintenance and operation [27].

In addition, most of the respondents agree to the implementation of telerehabilitation in hospital as the world advances to be technological arena. Telerehabilitation has been shown to be effective if only both patients and health care professionals buy into it [28], and since the procedure for telerehabilitation involves both parties to concord because there are two or more users involved with the telerehabilitation, the human interaction system needs to work and be usable from both sides, meaning that both rehabilitation professionals as well as clients need to be able to use the telerehabilitation [29]. Also, the issues bordering on ethical ground such as lack of confidentiality, patient privacy, and abusive use by patients, internet fraud and quackery have been identified in this research as challenges to implementation of telerehabilitation in Nigeria. Literature indicates effective approach in addressing issues such as clinical standards, ethics, professional licensing, liability and malpractice, privacy and confidentiality and reimbursement for rendered services in the field of telerehabilitation [30]. For instance, in Canada, the Canadian Alliance for Physiotherapy Regulators [31] documented that potential for increased risk of fraud because of the elimination of face-to-face contact, increased ease of unauthorized individuals posing as registered practitioners, increased potential for providers to practice outside of their scope of practice and potential for decreased security of information are concerns and challenges related to tele-practice. In order to address these challenges, there exist position statements for professionals in the field of telerehabilitation in addressing issues such as clinical and technical standards, administration, ethics, professional licensing, liability and malpractice, privacy and confidentiality $[2,30]$ in developed countries. On the contrary, there seems to be no widely documented health policy statements on ethics 
in telerehabilitation in Nigeria. This is evident in a study conducted by Ume and Salatian [32] on an approach to the implementation of an integrated computerized medical system in Nigeria.

Majority of the students in the study also believed such emerging branch (telerehabilitation) should be included in the curriculum of the school in order to equip and prepare them for post-graduation clinical practices as the world is moving into technological world. The need for the federal government to fund and also make policies that will make this young branch to thrive in the nation as it will benefit the remote places within the nation as well as the urban centres. Several students in this study believed telerehabilitation cannot replace physical consultations, and majority of them will not rely on telerehabilitation consultation unless only after seeing reports of patients being treated by it. This negative attitude towards the acceptance of telerehabilitation may be as a result of the known nature of physiotherapy services. Physiotherapy is viewed largely as hands-on and face-to-face interaction with the patient type of healthcare service delivery, and elimination of this physical contact with the use of telerehabilitation may seem or look like an 'inferior' physiotherapy services to many individuals. Concerted efforts on education and provision of evidence-based positive outcomes with the use of telerehabilitation may allay these fears. In fact, more than half of the respondents in this study expect a form of feedback to be sent after each session to aid their use of telerehabilitation. Moreover, there was significant association between attitude to use of telerehabilitation and level of study of students. The clinical students somewhat showed better attitude to telerehabilitation compared with non-clinical students. The clinical students are possibly more enlightened about telerehabilitation due to their level of education and clinical exposure.

In determining the interpretation and transferability of this study, consideration must be given to the potential limitation of self-reported nature of the data which can be affected by reporting bias.

\section{Conclusion}

Nigerian physiotherapy students have moderate awareness and high expectation for future telerehabilitation applications. However, a larger number of them hold negative attitude towards its use.

Data Availability The datasets generated during and/or analysed during the current study are available from the corresponding author on reasonable request.

\section{Declarations}

Ethics Approval Approval was obtained from the ethics committee of Obafemi Awolowo University, Nigeria (HREC No: IPHOAU/12/1449).
The procedures used in this study adhere to the tenets of the Declaration of Helsinki.

Consent to Participate Informed consent was obtained from all individual participants included in the study.

Conflict of Interest The authors declare that they have no conflict of interest.

\section{References}

1. Brennan DM, Mawson S, Brownsel S. Telerehabilitation: enabling the remote delivery of healthcare, rehabilitation and self management. Stud Health Technol Inform. 2009;145:231-48.

2. A Blueprint for Telerehabilitation Guidelines. American Telemedicine Association. 2010 [online] http://www.americantelemed.org/resources/ standards/ata-standards guidelines/blueprintfortelerehabilitationguidelines.pdf. Accessed 20 August 2019.

3. Theodorus D, Russell T. Telerehabilitation: current perspectives. Stud Health Technol Inform. 2008;131:191-209.

4. Cason J. Telerehabilitation: an adjunct service delivery model for early intervention services. Int J Telerehabil. 2011;3(1):19-30.

5. Jafni TI, Bahari M, Radman A. Understanding the implementation of telerehabilitation at pre-implementation stage: a systematic literature review. Procedia Computer Science. 2017;124:452-60.

6. Shamsuddin S, Yussof H, Mohamed S, Hanapiah FA, Ainudin HA. Telerehabilitation service with a robot for autism intervention. Procedia Computer Science; 2015. p. 349-54.

7. Rogante M, Grigioni M, Cordella D, Giacomozzi C. Ten years of telerehabilitation: a literature overview of technologies and clinical applications. NeuroRehabilitation. 2010;27(4):287-304.

8. Keerthi R, Chandra I, Deepak A. Can telerehabilitation add new dimension in the treatment of Osteoarthritis Knee? J Pain Relief. 2012;2(13):1-3.

9. Multani NK, Singh B, Garg S. Effectiveness of telemedicine services integrated into physiotherapeutic health care system. Journal of Exercise Science and Physiotherapy. 2006;2:87-91.

10. Russell TG, 'Tele-rehabilitation as successful as out-patient physiotherapy post total knee replacement'. J Bone Joint Surg. 2011;2(93):113-120.

11. Zheng H, Davies RJ, Black ND. "Web based monitoring system for home based rehabilitation with stroke patients', in Proceedings. $18^{\text {th }}$ IEEE Symposium on Computer-Based Medical Systems, Dublin, 2005; 419-424.

12. Yamane T. Statistics: An introductory Analysis. 2nd ed. New York: Harper and Row; 1967.

13. Dingli A, Seychell D. Who Are the Digital Natives? In: The New Digital Natives. Springer, Berlin, Heidelberg, 2015.

14. Pathipati AS, Azad TD, Jethwani K. Telemedical Education: Training Digital Natives in Telemedicine. J Med Internet Res. 2016;18(7):e193.

15. Aminu SA, Oyefesobi OO, Akerejola WO. Survey of user acceptance of mobile shopping in Nigeria. AICTTRA 2018 Conference Proceedings; 2018. pp. 132-139.

16. Adomi E, Okiy R, Ruteyan JO. A survey of cyber cafes in Delta State. Nigeria The Electronic Library. 2003;21(5):487-95.

17. Nweze CM. The use of ICT in Nigeria Universities: A Case Study of University, Ile-Ife. Libr Philos Pract. (e-journal). 2010;494.

18. Ajuwon GA. Computer and internet use by first year clinical and nursing students in a Nigerian Teaching hospital. BMC Med Inform Decis Mak. 2003;18(10):3.

19. Ogunyade Taiwo O, Oyibo Wellimngnton A. Use of CDROM MEDLINE by medical students of the college of 
Medicine, University of Lagos, Nigeria. J Med Internet Res. 2003, 31;5(1):e7.

20. Ibrahim SB, Fatiu AA, Abubakr AS, Ikechi TE, Abioye-Kuteyi EA, Adewale A. Knowledge and utilization of information technology among health care professionals and students in IleIfe, Nigeria; A case study of a University teaching hospital: J Med Internet Res. 2004;6(4):e45.

21. Beraterrechea A, Lee AG, Wilner JM, Jahangir E, Clapponi A, Rubinstein A. The impact of mobile health interventions on chronic disease outcomes in developing countries: A systematic review: Telemed J E Health. 2014;20(1):75-82.

22. Telerehabilitation, Background paper [online] 2012. Australian Physiotherapy Association, http://www.physiotherapy.asn.au. Accessed 2 June 2019.

23. Odole AC, Odunaiya NA, Ojo OD, Afolabi, K. Tele-physiotherapy in Nigeria: perceived challenges by physiotherapists to its implementation, International Journal of Telemedicine and Clinical Practices. 2015;1(2):186-196. J. Telemedicine and Clinical Practices, Vol. X, No. Y, pp.000-000 .of Telerehabilitation Guidelines \{online\} http://www.americantelemed.org/resources/standards/atastandards guidelines/blue-print-for-telerehabilitation-guidelines.pdf (accessed 20 August 2019).

24. Russell TG. Telerehabilitation: a coming of age. Aust J Physiother. 2009;55(1):5-6.

25. Rosen E. Twenty minutes in the life of a tele-home healthcare nurse. Telemedicine Today. 2001 [cited 2004 June 9].
26. Brennan DM, Barker LM. Human factors in the development and implementation of telerehabilitation systems. J Telemed Telecare. 2008;14(2):55-8.

27. Pramuka M, van Roosmalen L. Telerehabilitation technologies: accessibility and usability. Int J Telerehabil. 2009;1(1):85-98.

28. Peretti A, Amenta F, Tayebati SK, Nittari G, Mahdi SS. Telerehabilitation: Review of the state-of-the-art and areas of application, JMIR Rehabil Assist Technol. 2017;4(2):e7.

29. Bashshur RL. Telemedicine and health care. Telemedicine Journal and e-health. 2002;8(1):5-12.

30. National Initiative for Telehealth Guidelines 2003. National Initiative for Telehealth (NIFTE) Framework of Guidelines, Ottawa. http://cstsct.org/resources/FrameworkofGuidelines2003eng.pdf. Accessed 6 June 2019.

31. Considerations for Tele-practice in Physical Therapy in Canada 2006. Canadian Alliance of Physiotherapy Regulators [online]http://www.alliancept.org/pdfs/alliance_resources_ Telepractice_Guide_FINAL

32. Ume A, Salatian, A. 'An Approach to the implementation of an integrated computerized medical system in Nigeria'. Proceedings of the 1st International Technology, Education and Environment Conference 2011; pp.816-823, African Society for Scientific Research (ASSR).

Publisher's Note Springer Nature remains neutral with regard to jurisdictional claims in published maps and institutional affiliations. 